\title{
A New Post-PKS Modification Process in the Carbamoyltransferase Gene Inactivation Strain of Streptomyces hygroscopicus 17997
}

\author{
Yonghai Li, Weiqing He, Yucheng Wang, Yiguang Wang, Rongguang Shao
}

Received: April 13, 2008 / Accepted: May 27, 2008

(C) Japan Antibiotics Research Association

\begin{abstract}
Genetic manipulation of geldanamycin (GDM) producer Streptomyces species is a rational approach to understand biosynthesis processes and create new analogues. In this study, the carbamoyltransferase gene $g d m N$ was inactivated by insertion of an apramycinresistance gene aac3 (IV) into the genome of the geldanamycin-producing strain Streptomyces hygroscopicus 17997. GDM analogues produced by this mutant strain were isolated and characterized, such as new compound 4,5-dihydro-7-O-descarbamoyl-7-hydroxy-19-Oglycylgeldanamycin. This compound could be converted to compound 4,5-dihydro-19-O-glycylgeldanamycin, another new GDM analogue, by a strain of Streptomyces hygroscopicus 17997 in which the GDM-pks was inactivated. These new compounds exhibited reductions of cytotoxicity against HepG2 cancer cells, but increases of aqueous solubility. These results suggest that a new postpolyketide synthase modification was involved in this process to produce new GDM analogues.
\end{abstract}

Keywords geldanamycin, carbamoyltransferase gene, gene inactivation, post-polyketide synthase modification, geldanamycin analogues

Yi. Wang, R. Shao (Corresponding author), Y. Li, W. He, Yu. Wang: Key Lab of Biotechnology of Antibiotics, Ministry of Health, Institute of Medicinal Biotechnology, Peking Union Medical College, Chinese Academy of Medical Sciences, Beijing 100050, China,

E-mail: wangyh456@yahoo.com.cn or shaor@bbn.cn

\section{Introduction}

Geldanamycin (GDM) produced by Streptomyces hygroscopicus has been identified as a novel heat shock protein 90 (Hsp90) inhibitor [1, 2] and is a promising drug candidate in combating human tumor [3] and viral diseases [4 6]. Two GDM derivatives, the water-soluble 17-dimethylaminoethy-17-demethoxygeldanamycin (17DMAG) and 17-allylamino-17-demethoxy GDM (17AAG), are currently in phase I and II clinical trials, respectively [7 9].

GDM is a 19 -membered macrocyclic lactam that is related to the benzoquinone ansamycins, such as herbimycin and macbecin $[10,11]$. Biosynthesis of this class of compounds involves the assembly of 3-amino-5hydroxybenzoic acid as a starter unit. Following elongation with the acyl-Coenzyme A substrates malonyl-CoA, methylmalonyl-CoA, and 2-methoxymalonyl-CoA (ACP) [12 14], the presumed polyketide intermediate undergoes intramolecular lactamization by $\mathrm{GdmF}$ to form progeldanamycin [15], an initial polyketide synthase (PKS) product, which is, then converted to GDM by several postPKS modification steps, such as C-17 hydroxylation, C-17 $O$-methylation, C-21 oxidation, C-7 carbamoylation, and C4, 5 oxidation [15 17].

A set of type I PKS genes required for GDM biosynthesis have been cloned, sequenced and analyzed from several Streptomyces spp. [15, 19, 20]. Analysis of the GDM biosynthetic gene cluster has revealed the presence of a series of putative post-PKS modifying genes from $S$. hygroscopicus var. geldanus NRRL 3602 [15]. The genetic manipulation of the gene or domain of the GDM biosynthetic gene cluster is helpful for understanding the biosynthesis process, and creates new analogues of GDM 
$[16,18]$.

Our previous studies showed that the GDM biosynthetic gene cluster from GDM-producing strain S. hygroscopicus 17997 (GenBank accession number: AY179507) exhibited 93\% identity to $g d m N$ in NRRL 3602 [19]. BLAST search analysis indicated that $\mathrm{GdmN}$ is highly homologous to $O$ carbamoyltransferases, NovN, Asm21 and ORF7 [21 23], which are involved in the biosynthesis of novobiocin, ansamitocin and concanamycin A, respectively.

Here we report that the $g d m N$ in S. hygroscopicus 17997 was inactivated by insertion of an apramycin-resistance gene, aac3 (IV) [24], and that the known GDM analogue 4,5-dihydro-7-O-descarbamoyl-7-hydroxygeldanamycin and new analogue 4,5-dihydro-7-O-descarbamoyl-7hydroxy-19-O-glycylgeldanamycin were isolated from this $g d m N$ inactivation strain. The C-7 $O$-carbamoylation of GDMCT-1-1 was successfully occurred by bioconversion with a $g d m N$ gene-harboring strain. On the basis of the present results, we proposed that a new post-polyketide synthase modification was involved in this process to produce new GDM analogues.

\section{Materials and Methods}

\section{Bacterial Strains, Plasmids and Culture Conditions}

GDM-producing strain S. hygroscopicus 17997 was isolated from soil in China (Institute of Medicinal Biotechnology, Beijing). A GDM-pks inactivation strain was constructed by Dr. Weiqing He (Institute of Medicinal Biotechnology, Beijing) [25]. pGH112 vector was kindly provided by Prof. Keqian Yang (Institute of Microbiology, Chinese Academy of Sciences, Beijing) [26]. Escherichia coli ET12567/pUZ8002 was used as donor strain for conjugal transfer to S. hygroscopicus 17997. pUC18-Am ${ }^{\mathrm{R}}$ (apramycin resistance) used for gene inactivation was constructed in our lab [19] and $\mathrm{pKC} 1139-\mathrm{Km}^{\mathrm{R}}$ (kanamycin resistance) used in the complementation experiment was generated by insertion of a 1.0-kb BamHI - EcoRI fragment from pUC119-kan ${ }^{R}$ (provided by Prof. Huarong Tan, Institute of Microbiology, Chinese Academy of Sciences, China) into the same sites of pKC1139. E. coli ET12567/pUZ8002 and S. hygroscopicus 17997 were cocultured in Mannitol soya flour medium (MS) [27]. Media for the culture and fermentation of S. hygroscopicus 17997 were used as described by Gao et al. [28].

Construction of Plasmids, PCR Primers and Conditions An internal 949-bp EcoRI-BamHI fragment (fragment 1) and a 963-bp PstI-XbaI fragment (fragment 2) in $g d m N$ gene were obtained by PCR using primers N1 N4: N1 (fragment 1) (5'-CCGGAATTCACGGCCTTGGCCAGATCC-3' EcoRI), N2 (fragment 1) (5'-CGCGGATCCATCCACCCCGCCTCGCAC-3' BamHI), N3 (fragment 2) (5'-AAAACTGCAGGCCGTTGAGGCTGGAGTT-3' PstI), and N4 (fragment 2) (5'-CTAGTCTAGACCGACTGGTTTGGGTGAT-3' XbaI). The fragment 1 and 2 were then ligated with a $1.5-\mathrm{kb} B a m \mathrm{HI}$ PstI fragment carrying the apramycin-resistance gene from pUC18-Am ${ }^{\mathrm{R}}$ and then cloned into the EcoRI - XbaI sites of vector pGH112, to generate the replacement vector pGEX$g d m N$ (Fig. 1). For gene complementation, a $B g l I I$ fragment of the intact $g d m N$ gene was cloned in the $\mathrm{pKC} 1139-\mathrm{Km}^{\mathrm{R}}$ plasmid to generate the vector $\mathrm{pKC}-\mathrm{g} d m N$.

PCR reactions were performed with $S$. hygroscopicus 17997 and $g d m N$ gene inactivation mutant genomic DNA as templates at $96^{\circ} \mathrm{C}$ for 4 minutes, followed by 30 cycles of 40 seconds at $94^{\circ} \mathrm{C}$ and 40 seconds at $59 \sim 62^{\circ} \mathrm{C}, 1.5$ minutes at $72^{\circ} \mathrm{C}$, and an additional 5 minutes at $72^{\circ} \mathrm{C}$. The PCR products were analyzed and purified with agarose gel and PCR Clean-Up System (Promega), as described by the manufacturer.

\section{Isolation and Identification of $g d m \boldsymbol{N}$ Gene Mutant Strain}

Plasmid pGEX-gdmN was introduced into $S$. hygroscopicus 17997 by conjugation using E. coli ET12567/PUZ8002 as a donor. Conjugation was carried out on MS agar plates incubating at $28^{\circ} \mathrm{C}$ for 20 hours. Transconjugants were selected after overlaying the plates with $1.0 \mathrm{ml} \mathrm{H}_{2} \mathrm{O}$ containing $200 \mu \mathrm{g} / \mathrm{ml}$ nalidixic acid and $50 \mu \mathrm{g} / \mathrm{ml}$ apramycin. Plates were incubated at $28^{\circ} \mathrm{C}$ for $7 \sim 10$ days. Single colonies were picked and grown on MY agar plates ( $4.0 \mathrm{~g}$ yeast extract, $10 \mathrm{~g}$ malt extract, $4.0 \mathrm{~g}$ glucose, $15 \mathrm{~g}$ agar, per liter) for several rounds of non-selective incubation. Desired double crossover mutants $\left(\mathrm{Tsr}^{\mathrm{S}}\right.$ and $A m^{R}$ ) were obtained. To confirm the integration of the $A m^{R}$ gene into the $g d m N$ locus, genomic DNA was isolated from a number of transconjugants, and PCR was carried out using primers P1 (5'-CCCAAGCTTCTCGTGGACGGGTTGCT- $\left.3^{\prime}\right)$ and P2 (5'-CTAGTCTAGATCGAACGCCTCCACCTC-3').

\section{Fermentation and Purification}

The $g d m N$ mutant strain and gene complementation strain were grown on MY agar plates for 7 days for sporulation. Cultures were grown in seed medium for 2 days at $28^{\circ} \mathrm{C}$, and $3.0 \mathrm{ml}$ was used to inoculate $50 \mathrm{ml}$ of fermentation medium in $500-\mathrm{ml}$ shake flasks, which were cultured at $200 \mathrm{rpm}$ at $28^{\circ} \mathrm{C}$ for another 3 or 4 days. Fermentation broth was extracted with EtOAc, and the extract was dried to a crude solid by rotary evaporation at $37^{\circ} \mathrm{C}$. 


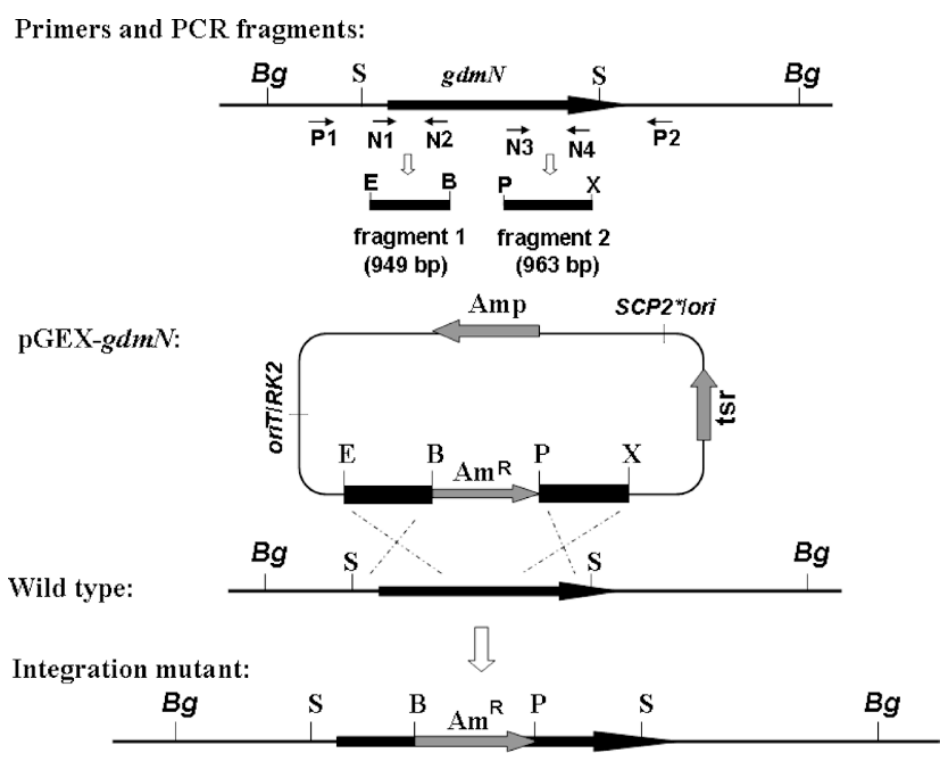

Fig. 1 Inactivation of $g d m N$ of the GDM biosynthetic gene cluster.

$A m^{R}$, apramycin resistance gene; tsr, thiostrepton resistance gene; $\mathrm{B}, \mathrm{BamHI}$; Bg, Bgll; E, EcoRI; P, Pstl; S, Sacl; X, Xbal.

Fractionation was initiated by silica gel chromatography using $\mathrm{CH}_{2} \mathrm{Cl}_{2} / \mathrm{MeOH}[19: 1$ (v/v, volume in volume)] as the mobile phase, and fractions obtained were pooled based on TLC and HPLC analysis. Pools containing compounds GDMCT-1-1 were further purified by preparative HPLC [Shimadzu ODS-C18; $150 \times 20 \mathrm{~mm}, \mathrm{MeOH} / \mathrm{H}_{2} \mathrm{O}, 14: 11$ $(\mathrm{v} / \mathrm{v}), 5.0 \mathrm{ml} / \mathrm{minute}$ ], to yield GDMCT-1-1 [retention time (Rt) $34.6,33 \mathrm{mg}$ ]. A similar procedure was applied to prepare the standard samples of GDM and 4,5-dihydro-7$O$-descarbamoyl-7-hydroxygeldanamycin (GDMCT-1-7)

\section{Complementation of $\boldsymbol{g d m} \boldsymbol{N}$ Gene}

Plasmid pKC-gdmN was introduced to the $g d m N$ inactivation strain by conjugation. $g d m N$ gene complementation strains were grown in fermentation medium containing apramycin $(50 \mu \mathrm{g} / \mathrm{ml})$ and kanamycin $(50 \mu \mathrm{g} / \mathrm{ml})$. Culture broth was extracted with ethyl acetate and analyzed by HPLC.

HPLC was carried out by a Shimadzu LC-6A with a diode array UV detector set at $304 \mathrm{~nm}$, fitted with a Diamonsil $^{\mathrm{TM}}$ RP-C18 column $(5.0 \mu \mathrm{m} ; 4.6 \times 150 \mathrm{~mm})$. Samples were eluted with a gradient $(1.0 \mathrm{ml} /$ minute $)$ of $\mathrm{MeOH} / \mathrm{H}_{2} \mathrm{O}(40: 60$ to $100: 0)$ over 30 minutes.

\section{Non-enzymatic Conversion Experiment of GDMCT-1-7}

$10 \mu \mathrm{l}$ of purified GDMCT-1-7 $(80 \mathrm{mg} / \mathrm{ml}$ in DMSO) was incubated with $50 \mathrm{ml}$ fermentation medium in $500-\mathrm{ml}$ shake flasks at $200 \mathrm{rpm}$ at $28^{\circ} \mathrm{C}$ for 3 days. Samples were monitored daily by HPLC and TLC analyzes.

\section{Bioconversion and Purification}

The GDM-pks inactivation strain was grown on MY agar plates for 7 days for sporulation. Culture was grown in seed medium for 2 days at $28^{\circ} \mathrm{C}$, then $5.0 \mathrm{ml}$ seed culture with addition of $10 \mu$ l GDMCT-1-1 (80 mg/ml in DMSO) was transferred into $50 \mathrm{ml}$ fermentation medium in $500-\mathrm{ml}$ shake flasks and incubated at $200 \mathrm{rpm}$ at $28^{\circ} \mathrm{C}$ for 4 days. 4.0 liters fermentation broth was extracted twice with EtOAc and the extract was dried to a crude solid by rotary evaporation at $37^{\circ} \mathrm{C}$. Fractionation was initiated by silica gel chromatography using $\mathrm{CH}_{2} \mathrm{Cl}_{2} / \mathrm{MeOH}[16: 1$ (v/v)] as mobile phase, and fractions obtained were pooled based on TLC and HPLC analysis. Pools containing compounds GDMCT-1-2 were further purified by preparative HPLC [Waters 2996 ODS-C18; $150 \times 20 \mathrm{~mm}, \mathrm{MeOH} / \mathrm{H}_{2} \mathrm{O}, 14: 11$ (v/v), $5.0 \mathrm{ml} /$ minute], to yield GDMCT-1-2 (Rt 23.1, $10 \mathrm{mg})$.

\section{Cytotoxicity Assay of GDM Analogues}

The compounds were dissolved in DMSO as $100 \mathrm{mg} / \mathrm{ml}$ stock solutions before use and stored at $-20^{\circ} \mathrm{C}$. Human liver cancer HepG2 cells (the American Type Culture Collection, Rockville, MD) were cultured in MEM medium supplemented with $10 \%$ Fetal Bovine Serum. HepG2 cells were maintained in a $37^{\circ} \mathrm{C}, 5.0 \% \quad \mathrm{CO}_{2}$ humidified incubator. For cytotoxicity assays, 5000 of HepG2 cells were plated in $100 \mu \mathrm{l}$ per well into 96-well micro titer plates. Cells were allowed to adhere for 24 hours. Each compound ranging from 0.1 to $100 \mu \mathrm{g} / \mathrm{ml}$ in $100 \mu \mathrm{l}$ was added to cells in duplicate wells. After 24 hours incubation, 
cell viability was determined by sulforhodamine B (SRB) assay [29]. $\mathrm{IC}_{50}$ is defined as the concentration of compounds required for inhibiting cell growth by $50 \%$.

\section{Water Solubility Test of GDM Analogues}

Standard curves of relationship between OD251 and OD304 values and concentrations of GDM analogues in $\mathrm{MeOH}$ were established. Saturated aqueous solution of GDM analogues was made in $50 \mathrm{mM}$ PBS at $\mathrm{pH} 7.0$ with magnetic stir at room temperature for 12 hours in dark, and then centrifuged at $100,000 \mathrm{~g}$ for 10 minutes at $4^{\circ} \mathrm{C}$. Supernatant were measured by BECKMAN DU ${ }^{\circledR} 800$ nucleic acid/protein analyzer at OD251 (GDMCT-1-1 and GDMCT-1-2) and OD304 (GDMCT-1-7 and GDM). The concentration of the saturated aqueous solutions was determined according to standard curves.

\section{Results}

\section{Inactivation of $\boldsymbol{g} d \boldsymbol{m} \boldsymbol{N}$ Gene}

Inactivation of $g d m N$ in S. hygroscopicus 17997 was performed by insertion of the $\mathrm{Am}^{\mathrm{R}}$ gene into the $g d m N$ locus as shown in Fig. 1, and confirmed by PCR analysis using P1 and P2 primers. Predicted sizes (3.1-kb and 4.5$\mathrm{kb})$ of PCR products were obtained using the genome DNA of $S$. hygroscopicus 17997 and $g d m N$ inactivation strain as templates, respectively. Complementation analysis was performed to ensure the phenotypic change of the $g d m N$ inactivation strain was solely caused by the inactivation of $g d m N$.

HPLC analysis showed that the ability of GDM production was completely lost by $g d m N$ inactivation (Fig. 2B) and restored by its complementation (Fig. 2C). In contrast, two major components (GDMCT-1-1 and GDMCT-1-7) with Rt 12.9 and 25.8 minutes were observed in the $g d m N$ inactivation strain (Fig. 2B). It is interesting to note that the ratio of GDMCT-1-1 and GDMCT-1-7 produced by the $g d m N$ inactivation strain was changed in a time dependent manner. As shown in Fig. 3, GDMCT-1-7 was produced early and then gradually declined after 3 days fermentation, meanwhile GDMCT-1-1 had significantly accumulated during day 4 and day 5 .

\section{Structural Elucidation of GDMCT-1-7 and GDMCT-1-1} Compound GDMCT-1-7 displayed ESI-MS patterns resembling those of GDM. The ${ }^{1} \mathrm{H}-\mathrm{NMR},{ }^{13} \mathrm{C}-\mathrm{NMR}$ and MS data were identical with those of compound 3 [20] and were consistent with the molecular formula $\mathrm{C}_{28} \mathrm{H}_{41} \mathrm{~N}_{1} \mathrm{O}_{8}$ obtained by negative HRFAB-MS $\left([\mathrm{M}-\mathrm{H}]^{-}, \quad \mathrm{m} / \mathrm{z}\right.$ 518.2740). Accordingly, this compound is the 4,5-dihydro7-O-descarbamoyl-7-hydroxygeldanamycin (GDMCT-1-7) being the main product of the carbamoyltransferase gene inactivation strain of $S$. hygroscopicus JCM4427 as
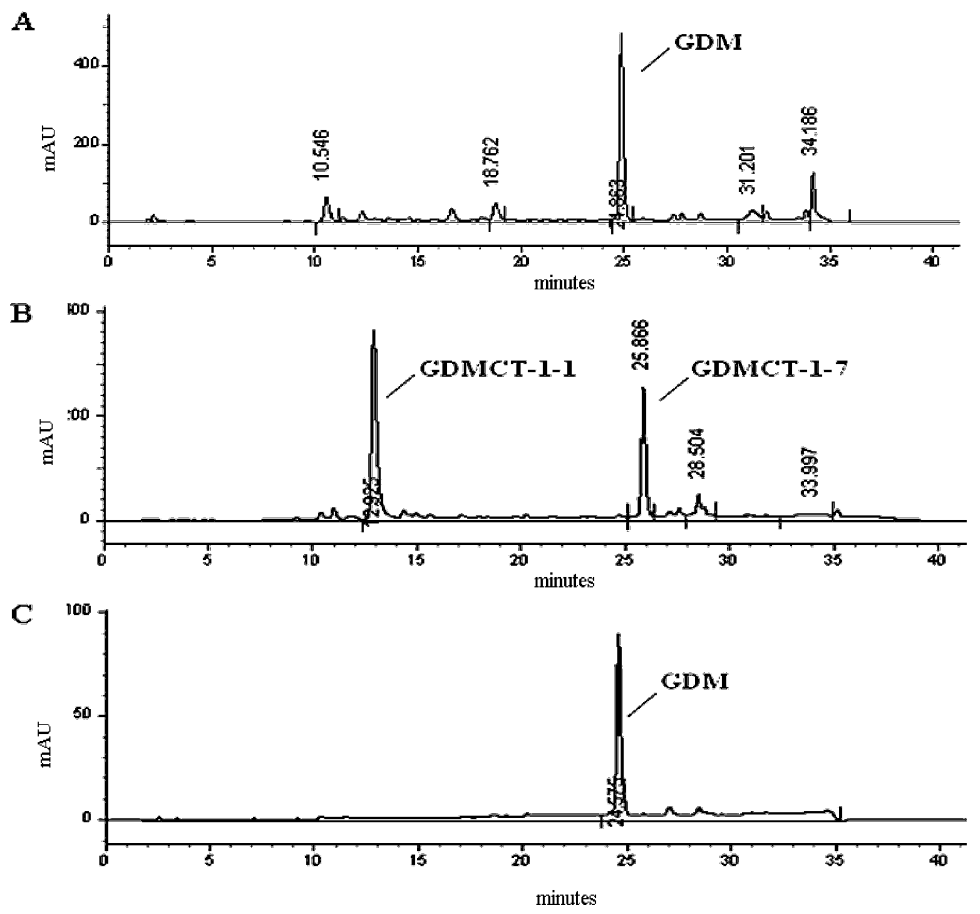

Fig. 2 HPLC analysis of GDM analogues produced by wild-type and gdmN inactivation strains of S. hygroscopicus 17997.

A, wild-type; B, gdmN inactivation strain; C, gdmN complement. 
reported by Hong et al. [20].

An analysis of the 1D and 2D NMR spectra of GDMCT$1-1$ suggested that it is a derivative of GDM. From the ${ }^{1} \mathrm{H}-$

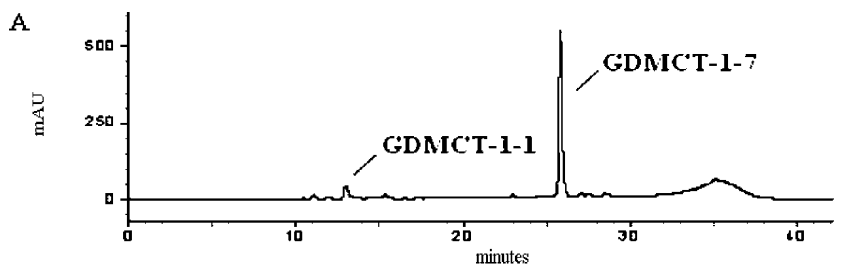

B

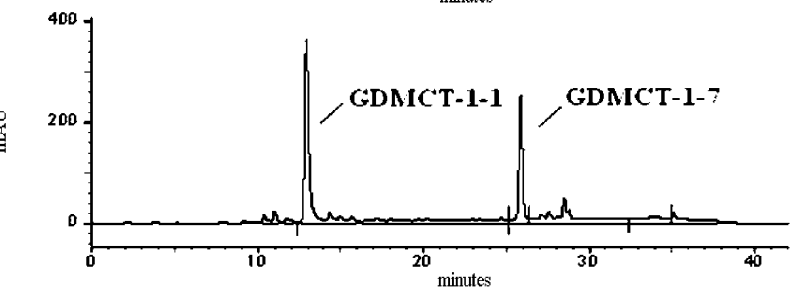

C
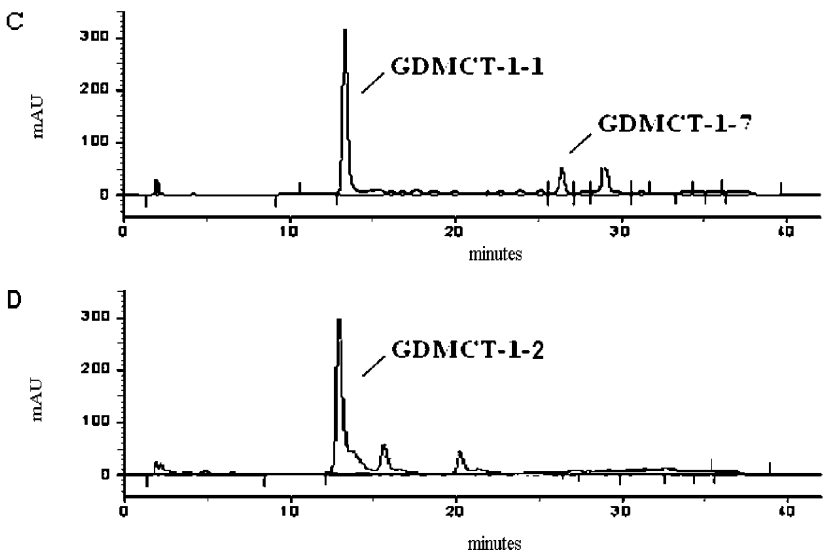

Fig. 3 HPLC analysis of GDM analogues produced by $g d m N$ inactivation strain of S. hygroscopicus 17997 at the fermentation times of 3 (A), 4 (B) and 5 (C) days, and bioconversion of GDMCT-1-1 for 4 days (D). and ${ }^{13} \mathrm{C}-\mathrm{NMR}$ spectra of GDMCT-1-1, the upfield shift of C-7 signals at $\delta_{\mathrm{H}} 3.87$ and $\delta_{\mathrm{C}} 79.69$ indicated that GDMCT-1-1 has a free hydroxyl group at C-7 rather than a carbamoyl group, as expected. Furthermore, two olefinic methine signals (C-4 and C-5) of GDMCT-1-1 were not detected, suggesting that its cis double bond had been hydrogenated. The signal of C-19 hydrogen was not detected, but an additional carbonyl signal $\left(\delta_{\mathrm{C}} 165.52\right)$ and a secondary carbon $\left(\delta_{\mathrm{C}} 29.21\right)$ hydrogen $\left(\delta_{\mathrm{H}} 3.55\right)$ signal which has correlation with the $\mathrm{C}-19$ carbon signal $\left(\delta_{\mathrm{C}}\right.$ 117.90) (Fig. 4) of the benzene ring as supported by HMQC (heteronuclear multiple quantum coherence) and HMBC (heteronuclear multiple bond coherence) spectra appeared, this suggesting that there is a $O$-glycyl group at C-19. A combination of COSY (combination of correlation spectroscopy), NOESY (nuclear overhauser effect spectroscopy), NMR and IR (infrared spectroscopy) data were used to assign the ${ }^{1} \mathrm{H}-$ and ${ }^{13} \mathrm{C}-\mathrm{NMR}$ data unambiguously (Table 1). Accordingly, the structure of this new metabolite was elucidated as 4,5-dihydro-7-Odescarbamoyl-7-hydroxy-19-O-glycylgeldanamycin (GDMCT-1-1) with molecular formula $\mathrm{C}_{30} \mathrm{H}_{44} \mathrm{~N}_{2} \mathrm{O}_{10} \mathrm{Na}$ which was consistent with results obtained by positive HRFAB-MS ( $m / z$ 615.2996).

\section{Microbial Conversion of GDMCT-1-1}

In order to clarify the possible C-7 carbamoylation of GDMCT-1-1, a GDM-pks inactivation strain of $S$. hygroscopicus 17997, which did not produce GDM but retained the $g d m N$ encoding enzyme activity, was used in the microbial conversion of GDMCT-1-1. The results indicated that a compound GDMCT-1-2 was detected with Rt 12.3 minutes by HPLC analysis (Fig. 3D).

Compound GDMCT-1-2 displayed ESI-MS patterns that

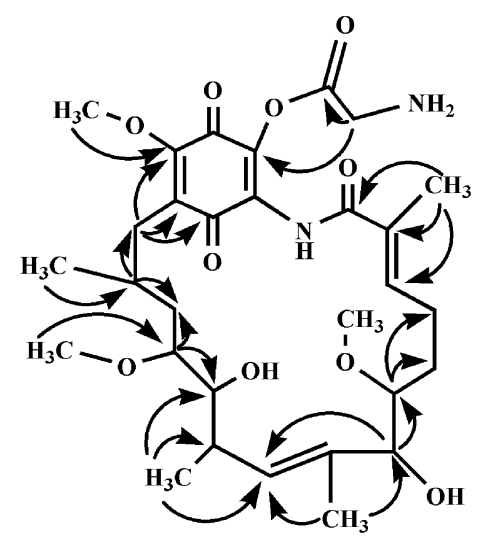

GDMCT-1-1

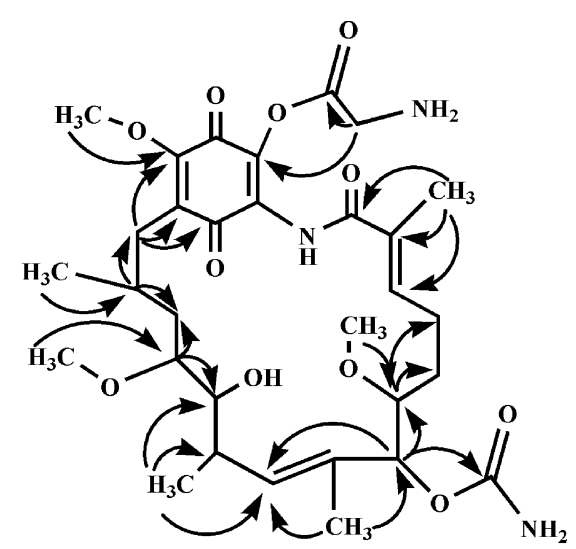

GDMCT-1-2

$\rightarrow \quad:{ }^{1} \mathrm{H}-{ }^{13} \mathrm{C}$ long-range coupling

Fig. $4 \quad{ }^{1} \mathrm{H}_{-1}^{13} \mathrm{C}$ HMBC correlations analysis of GDMCT-1-1 and GDMCT-1-2. 
Table $1{ }^{1} \mathrm{H}$ - and ${ }^{13} \mathrm{C}-\mathrm{NMR}$ data of compound GDMCT-1-1 $(500 \mathrm{MHz})$ and GDMCT-1-2 $(600 \mathrm{MHz})$

\begin{tabular}{|c|c|c|c|c|}
\hline \multirow{2}{*}{ Position } & \multicolumn{2}{|c|}{$\begin{array}{c}\delta_{\mathrm{H}} \\
\left(\mathrm{CD}_{3} \mathrm{OD}\right)\end{array}$} & \multicolumn{2}{|c|}{$\begin{array}{c}\delta_{\mathrm{C}} \\
\left(\mathrm{CD}_{3} \mathrm{OD}\right)\end{array}$} \\
\hline & GDMCT-1-1 & GDMCT-1-2 & GDMCT-1-1 & GDMCT-1-2 \\
\hline 1 & - & - & 176.23 & 177.61 \\
\hline 2 & - & - & 129.88 & 131.31 \\
\hline $2-\mathrm{CH}_{3}$ & 1.80 & 1.73 & 12.21 & 13.57 \\
\hline 3 & 5.62 & 5.51 & 133.44 & 134.52 \\
\hline 4 & $2.05 / 1.99$ & $1.89 / 2.02$ & 23.40 & 24.56 \\
\hline 5 & $1.08 / 0.98$ & $0.88 / 0.98$ & 29.90 & 31.09 \\
\hline 6 & 3.06 & 2.98 & 81.92 & 82.50 \\
\hline $6-\mathrm{OCH}_{3}$ & 3.44 & 3.36 & 57.58 & 59.39 \\
\hline 7 & 3.87 & 4.86 & 79.69 & 81.92 \\
\hline 8 & - & - & 133.44 & 131.12 \\
\hline $8-\mathrm{CH}_{3}$ & 1.45 & 1.38 & 10.41 & 12.37 \\
\hline 9 & 5.04 & 5.05 & 130.70 & 134.01 \\
\hline 10 & 2.45 & 2.35 & 34.74 & 36.23 \\
\hline $10-\mathrm{CH}_{3}$ & 1.08 & 1.04 & 17.33 & 18.73 \\
\hline 11 & 3.65 & 3.50 & 72.94 & 74.05 \\
\hline 12 & 3.14 & 2.47 & 81.24 & 82.06 \\
\hline $12-\mathrm{OCH}_{3}$ & 3.33 & 3.24 & 55.41 & 56.77 \\
\hline 13 & $1.76 / 0.98$ & $1.70 / 0.88$ & 32.15 & 33.23 \\
\hline 14 & 2.05 & 1.92 & 31.33 & 32.37 \\
\hline $14-\mathrm{CH}_{3}$ & 0.7 & 0.61 & 16.39 & 17.20 \\
\hline 15 & $3.06 / 2.58$ & $2.97 / 2.50$ & 29.90 & 31.45 \\
\hline 16 & - & - & 120.04 & 121.23 \\
\hline 17 & - & - & 146.70 & 148.10 \\
\hline $17-\mathrm{OCH}_{3}$ & 3.69 & 3.57 & 60.01 & 61.40 \\
\hline 18 & - & - & 120.03 & 121.67 \\
\hline 19 & - & - & 117.90 & 119.10 \\
\hline 20 & - & - & 123.20 & 124.66 \\
\hline 21 & - & - & 148.62 & 150.08 \\
\hline 7-Oㅡㅇㅔ ${ }_{2}$ & - & - & - & 159.02 \\
\hline $19-\mathrm{O} \underline{\mathrm{C}} \mathrm{OCH}{ }_{2} \mathrm{NH}_{2}$ & - & - & 165.52 & 166.85 \\
\hline $19-\mathrm{OCOCH}{ }_{2} \mathrm{NH}_{2}$ & $3.55 / 3.33$ & $3.47 / 3.21$ & 29.21 & 30.50 \\
\hline
\end{tabular}

resembled those of GDMCT-1-1. An analysis of the 1D and 2D NMR spectra of GDMCT-1-2 suggested that it was a derivative of GDMCT-1-1. From the ${ }^{1} \mathrm{H}$ - and ${ }^{13} \mathrm{C}-\mathrm{NMR}$ spectra of GDMCT-1-2, the upfield shift of C-7 signals at $\delta_{\mathrm{H}} 4.86$ and $\delta_{\mathrm{C}} 81.92$ indicated that GDMCT-1-2 had a carbamoyl group at $\mathrm{C}-7$ rather than a free hydroxyl group (Fig. 4), as expected; this was coincident with the new carbonyl $\mathrm{C}$ signal at $\delta_{\mathrm{C}}$ 159.02. These results were consistent with the molecular formula $\mathrm{C}_{31} \mathrm{H}_{45} \mathrm{~N}_{3} \mathrm{O}_{11} \mathrm{Na}$ obtained by positive HRFAB-MS ( $\mathrm{m} / \mathrm{z}$ 658.2972). A combination of COSY, HMQC, HMBC and NMR data were used to assign the ${ }^{1} \mathrm{H}-$ and ${ }^{13} \mathrm{C}-\mathrm{NMR}$ data
Table 2 Solubility and cytotoxicity of GDM analogues

\begin{tabular}{lcr}
\hline Compound & Solubility $(\mathrm{mg} / \mathrm{ml})$ & $\mathrm{IC}_{50}(\mu \mathrm{M})$ \\
\hline GDM & 0.017 & 0.59 \\
GDMCT-1-1 & 0.402 & 277.89 \\
GDMCT-1-2 & 0.573 & 302.30 \\
GDMCT-1-7 & 0.039 & 24.55 \\
\hline
\end{tabular}

unambiguously (Table 1). Compared to GDMCT-1-1, the structure of this new metabolite was elucidated as 4,5dihydro-19-O-glycylgeldanamycin (GDMCT-1-2). 


\section{Water Solubility and Cytotoxicity of GDM Analogues}

As shown in Table 2, the results of the solubility assay showed that the solubility of GDMCT-1-1 and GDMCT-1-2 was approximately 23 -fold higher than that of GDM in aqueous solution.

The cytotoxicity of the compounds against HepG2 cells was investigated. As shown in Table 2, the results indicated that the cytotoxicity of GDMCT-1-1 and GDMCT-1-7 was almost 41 to 471 -fold lower than that of GDM.

\section{Discussion}

To our best knowledge, this is the first report that GDMCT1-1 and GDMCT-1-2 were produced by engineered biosynthesis. The new compound GDMCT-1-1 was purified from the fermentation broth of the $g d m N$ inactivation strain, which was not detected in wild-type $S$. hygroscopicus 17997. It has been reported that this compound is not produced in the same gene (gel8) inactivation strain of S. hygroscopicus JCM4427 [20].

It is notable that inactivation of $g d m N$ gene in $S$. hygroscopicus 17997 resulted in production of GDMCT-11 (Fig. 3A C). The accumulation of descarbamoylated compounds GDMCT-1-7 and GDMCT-1-1 in the $g d m N$ inactivation strain of S. hygroscopicus 17997 confirmed that the $g d m N$ encodes a carbamoyltransferase. We observed that GDMCT-1-7 was produced at an early stage, and then declined simultaneously with an increase of GDMCT-1-1 (Fig. 3A C), suggesting that GDMCT-1-7 might serve as a precursor for the biosynthesis of GDMCT1-1 at least in the $g d m N$ inactivation strain of $S$. hygroscopicus 17997. GDMCT-1-1 could be converted to GDMCT-1-2 by the $g d m N$ containing strain of $S$. hygroscopicus 17997.

In our study, GDMCT-1-1 was not monitored in the nonenzymatic conversion experiment of GDMCT-1-7 (data not shown), indicating that GDM C-19 modification enzymes (glycyltransferase or a bifunctional C-19 hydroxy/glycyltransferase) were possibly involved in GDMCT-1-1 biosynthesis in the $g d m N$ inactivation strain of S. hygroscopicus 17997. It has been reported that an $\mathrm{N}$ glycyltransferase is discovered in $S$. sannanensis IFO 14239 (sannamycin-producer), and the gene sequences of similar glycyltransferase have been detected in other aminoglycoside antibiotic producers by DNA hybridization [30]. Up to now, there has been no report that the biological modification of GDM analogues at C-19, although this
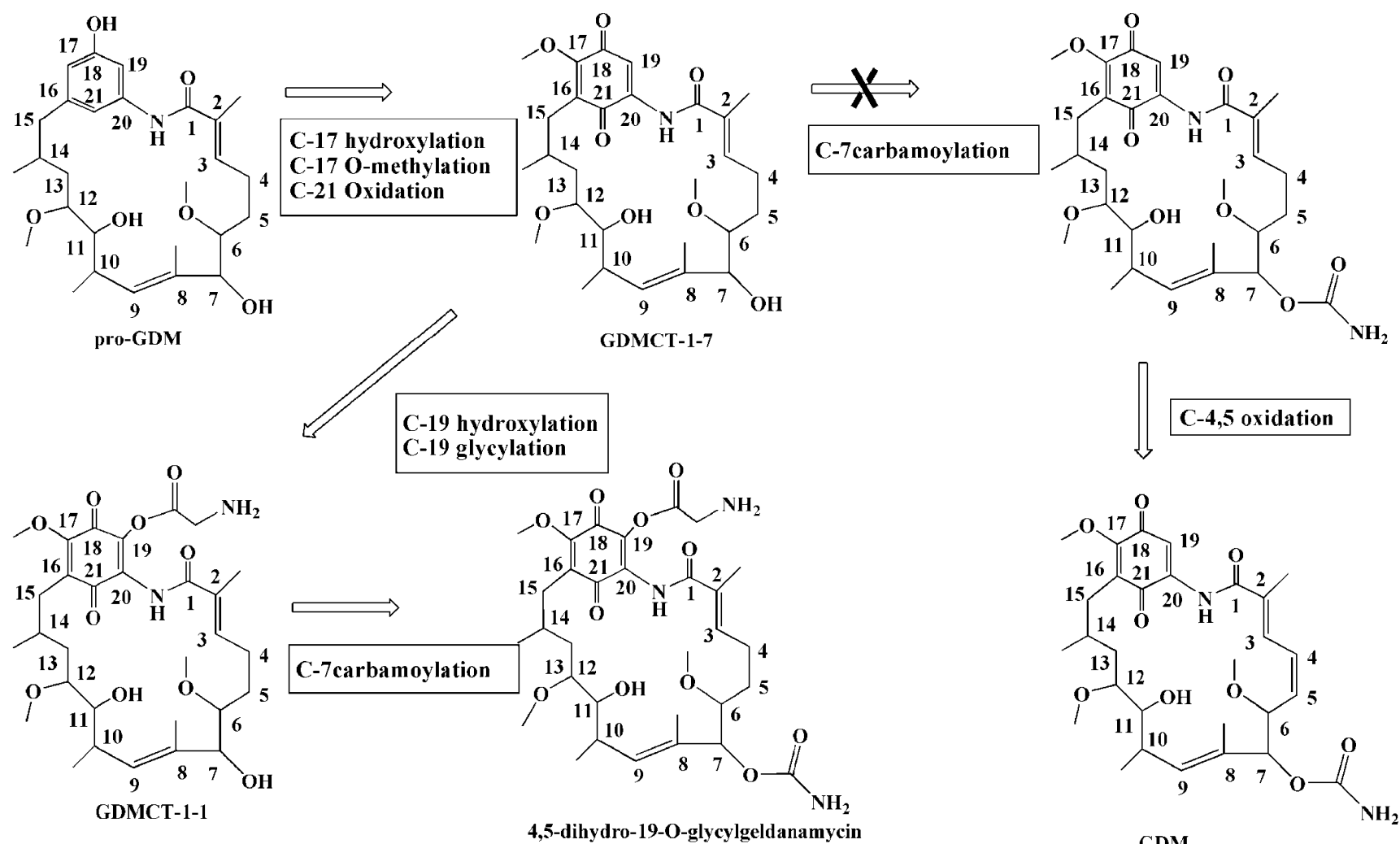

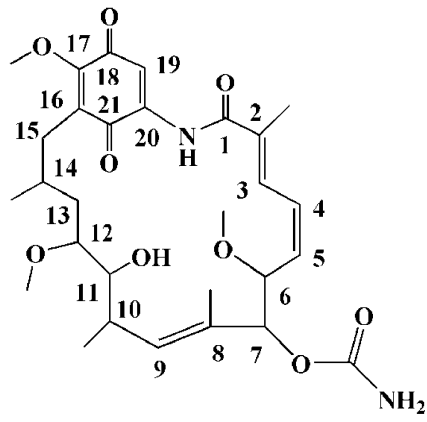

GDM

GDMCT-1-2

Fig. 5 The proposed post-PKS modification process of GDM analogues biosynthesis. 
position can be nonenzymatically modified by glutathione [31]. GDMCT-1-1 was not observed in the wild-type S. hygroscopicus 17997 strain, because its intermediate product (GDMCT-1-7, a possible substrate of the putative glycyltransferase) is rapidly carbamoylated by $\mathrm{GdmN}$, and therefore is not available for latter glycylation reaction. The conversion of GDMCT-1-7 to GDMCT-1-1 in the $g d m N$ inactivation strain fermentation process may suggest that this is likely a spurious cellular event caused by a series of enzymes that are not directly involved in the biosynthesis of GDM. The mechanism of the $O$-glycylation of GDMCT1-7 C-19 will be investigated in further experiments of gene expression and purified enzymes.

It is interesting that the GDM analogues GDMCT-1-7, GDMCT-1-1 and some other precursors [32] can be recognized by $\mathrm{C}-7$ carbamoylase, which indicates that the C-7 carbamoylation enzyme possesses a rather broad substrate specificity. GDMCT-1-1 and GDMCT-1-2 do not carry a double bond at the C-4 and C-5 positions, the possible reason for the inhibition of $\mathrm{C}-4,5$ oxidation of GDMCT-1-1 and GDMCT-1-2 is currently undergoing investigation. Taken together, we speculate a new post-PKS modification process of GDM analogue biosynthesis in S. hygroscopicus 17997 as described in Fig. 5.

So far, the effective chemical modification of GDM is mostly restricted to one region of the compound, the C-17 position of the benzoquinone moiety [33 35]. However, due to the occurrence of resistance and the hepatotoxicity of the current analogues, new GDM analogues with improved efficacy, reduced toxicity and favorable pharmacological profiles are in great demand [33, 36]. Consequently, clear understand of GDM biosynthesis and the discovery of new post-tailoring enzymes should be useful for the development of new analogues.

Although the two new compounds GDMCT-1-1 and GDMCT-1-2 showed reductions of cytotoxicity against HepG2 cells (Table 2), they exhibited a notable increase of water-solubility relative to GDM and GDMCT-1-7 (Table 2 ), which is an important characteristic for the innovation of GDM-derived compounds. Our results provide a new modification position of GDM and contribute to better understanding of GDM biosynthesis, and this would provide valuable information for the design of new GDM analogues with enhanced biological activity.

Acknowledgements We thank Prof. Wen-zao Jin (the Institute of Medicinal Biotechnology, Beijing, China) and Dr. Xiang Li (the Agriculture and Agri-Food, Saskatoon Research Center, Canada) for assistance in interpretation with NMR spectra analysis. This work was supported in part by grant of the National 973 Program of Ministry of Sciences and Technology
(2002CB513108).

\section{References}

1. Whitesell L, Mimnaugh EG, De Costa B, Myers CE, Neckers LM. Inhibition of heat shock protein HSP90pp60v-src heteroprotein complex formation by benzoquinone ansamycins: essential role for stress proteins in oncogenic transformation. Proc Natl Acad Sci USA 91: 8324-8328 (1994)

2. Neckers L, Schulte TW, Mimnaugh E. Geldanamycin as a potential anti-cancer agent: its molecular target and biochemical activity. Invest New Drugs 17: 361-373 (1999)

3. Goetz MP, Toft D, Reid J, Ames M, Stensgard B, Safgren S, Adjei AA, Sloan J, Atherton P, Vasile V, Salazaar S, Adjei A, Croghan G, Erlichman C. Phase I trial of 17-allylamino-17demethoxygeldanamycin in patients with advanced cancer. J Clin Oncol 23: 1078-1087 (2005)

4. Hung JJ, Chung CS, Chang W. Molecular chaperone Hsp90 is important for vaccinia virus growth in cells. J Virol 76: 1379-1390 (2002)

5. Li YH, Tao PZ, Liu YZ, Jiang JD. Geldanamycin, a ligand of heat shock protein 90, inhibits the replication of herpes simplex virus type 1 in vitro. Antimicrob Agents Chemother 48: 867-872 (2004)

6. Connor JH, McKenzie MO, Parks GD, Lyles DS. Antiviral activity and RNA polymerase degradation following Hsp90 inhibition in a range of negative strand viruses. Virology 362: 109-119 (2007)

7. Banerji U, Walton M, Raynaud F, Grimshaw R, Kelland L, Valenti M, Judson I, Workman P. Pharmacokineticpharmacodynamic relationships for the heat shock protein 90 molecular chaperone inhibitor 17-allylamino, 17demethoxygeldanamycin in human ovarian cancer xenograft models. Clin Cancer Res 11: 7023-7032 (2005)

8. Smith V, Sausville EA, Camalier RF, Fiebig HH, Burger AM. Comparison of 17-dimethylaminoethylamino-17demethoxy-geldanamycin (17-DMAG) and 17-allylamino17-demethoxygeldanamycin (17-AAG) in vitro: effects on Hsp90 and client proteins in melanoma models. Cancer Chemother Pharmacol 56: 126-137 (2005)

9. Sharp S, Workman P. Inhibitors of the HSP90 molecular chaperone: current status. Adv Cancer Res 95: 323-348 (2006)

10. DeBoer C, Meulman PA, Wnuk RJ, Peterson DH. Geldanamycin, a new antibiotic. J Antibiot 23: 442-447 (1970)

11. Muroi M, Izawa M, Kosai Y, Asai M. Macbecins I and II, new antitumor antibiotics. II. Isolation and characterization. J Antibiot 33: 205-212 (1980)

12. Wu K, Chung L, Revill WP, Katz L. Reeves CD. The FK520 gene cluster of Streptomyces hygroscopicus var. ascomyceticus (ATCC 14891) contains genes for biosynthesis of unusual polyketide extender units. Gene 251: 
81-90 (2000)

13. Carroll BJ, Moss SJ, Bai L, Kato Y, Toelzer S, Yu TW, Floss HG. Identification of a set of genes involved in the formation of the substrate for the incorporation of the unusual "glycolate" chain extension unit in ansamitocin biosynthesis. J Am Chem Soc 124: 4176-4177 (2002)

14. Kato Y, Bai L, Xue Q, Revill WP, Yu TW, Floss HG. Functional expression of genes involved in the biosynthesis of the novel polyketide chain extension unit, methoxymalonyl-acyl carrier protein, and engineered biosynthesis of 2-desmethyl-2-methoxy-6-deoxyerythronolide B. J Am Chem Soc 124: 5268-5269 (2002)

15. Rascher A, Hu Z, Viswanathan N, Schirmer A, Reid R, Nierman WC, Lewis M, Hutchinson CR. Cloning and characterization of a gene cluster for geldanamycin production in Streptomyces hygroscopicus NRRL 3602. FEMS Microbiol Lett 218: 223-230 (2003)

16. Patel K, Piagentini M, Rascher A, Tian ZQ, Buchanan GO, Regentin R, Hu Z, Hutchinson CR, McDaniel R. Engineered biosynthesis of geldanamycin analogs for Hsp90 inhibition. Chem Biol 11: 1625-1633 (2004)

17. Rascher A, Hu Z, Buchanan GO, Reid R, Hutchinson CR. Insights into the biosynthesis of the benzoquinone ansamycins geldanamycin and herbimycin, obtained by gene sequencing and disruption. Appl Environ Microbiol 71: 4862-4871 (2005)

18. Vetcher L, Tian ZQ, McDaniel R, Rascher A, Revill WP, Hutchinson $\mathrm{CR}, \mathrm{Hu} \mathrm{Z}$. Rapid engineering of the geldanamycin biosynthesis pathway by Red/ET recombination and gene complementation. Appl Environ Microbiol 71: 1829-1835 (2005)

19. He WQ, Wang YG. Cloning and analysis of geldanamycin partial biosynthetic gene cluster of Streptomyces hygroscopicus 17997. Sheng Wu Gong Cheng Xue Bao 22: 902-906 (2006)

20. Hong YS, Lee D, Kim W, Jeong JK, Kim CG, Sohng JK, Lee JH, Paik SG, Lee JJ. Inactivation of the carbamoyltransferase gene refines post-polyketide synthase modification steps in the biosynthesis of the antitumor agent geldanamycin. J Am Chem Soc 126: 11142-11143 (2004)

21. Steffensky M, Muhlenweg A, Wang ZX, Li SM. Heide L. Identification of the novobiocin biosynthetic gene cluster of Streptomyces spheroides NCIB 11891. Antimicrob Agents Chemother 44: 1214-1222 (2000)

22. Yu TW, Bai L, Clade D, Hoffmann D, Toelzer S, Trinh KQ, $\mathrm{Xu}$ J, Moss SJ, Leistner E, Floss HG. The biosynthetic gene cluster of the maytansinoid antitumor agent ansamitocin from Actinosynnema pretiosum. Proc Natl Acad Sci USA 99: 7968-7973 (2002)

23. Haydock SF, Appleyard AN, Mironenko T, Lester J, Scott N, Leadlay PF. Organization of the biosynthetic gene cluster for the macrolide concanamycin A in Streptomyces neyagawaensis ATCC 27449. Microbiology (Reading, England) 151: 3161-3169 (2005)

24. Richardson MA, Kuhstoss S, Solenberg P, Schaus NA,
Rao RN. A new shuttle cosmid vector, pKC505, for Streptomycetes: its use in the cloning of three different spiramycin-resistance genes from a Streptomyces ambofaciens library. Gene 61: 231-241 (1987)

25. He WQ, Li JY, Sun GZ, Liu YY, Wang YG. Detection of fermentation prodcuts from Streptomyces hygroscopicus 17997 by HPLC analysis. Chin J Antibiot 31: 168-171 (2006)

26. Mo HB, Bai LQ, Wang SL, Yang KQ. Construction of efficient conjugal plasmids between Escherichia coli and Streptomycetes. Sheng Wu Gong Cheng Xue Bao 20: 662-666 (2004)

27. Kieser T, Bibb MJ, Buttner MJ, Chater KF, Da H. Practical Streptomyces Genetics. John Innes Centre, 2000: page 409

28. Gao QJ, Shang GD, Yang Y, Sun GZ, Wang YG. Cloning and molecular analysis of geldanamycin biosynthetic genes from Streptomyces hygroscopicus. Chinese J Antibiot 27: 13-27 (2002)

29. Ge J, Normant E, Porter JR, Ali JA, Dembski MS, Gao Y, Georges AT, Grenier L, Pak RH, Patterson J, Sydor JR, Tibbitts TT, Tong JK, Adams J, Palombella VJ. Design, synthesis, and biological evaluation of hydroquinone derivatives of 17-amino-17-demethoxygeldanamycin as potent, water-soluble inhibitors of Hsp90. J Med Chem 49: 4606-4615 (2006)

30. Ohta T, Hashimoto E, Hasegawa M. Characterization of sannamycin A-nonproducing mutants of Streptomyces sannanensis. J Antibiot 45: 289-291 (1992)

31. Cysyk RL, Parker RJ, Barchi JJ, Jr, Steeg PS, Hartman NR, Strong JM. Reaction of geldanamycin and C17-substituted analogues with glutathione: product identifications and pharmacological implications. Chem Res Toxicol 19: 376-381 (2006)

32. Kim W, Lee JS, Lee D, Cai XF, Shin JC, Lee K, Lee CH, Ryu S, Paik SG, Lee JJ, Hong YS. Mutasynthesis of geldanamycin by the disruption of a gene producing starter unit: generation of structural diversity at the benzoquinone ring. ChemBioChem 8: 1491-1494 (2007)

33. Schnur RC, Corman ML, Gallaschun RJ, Cooper BA, Dee MF, Doty JL, Muzzi ML, DiOrio CI, Barbacci EG, Miller $\mathrm{PE}$, et al. erbB-2 oncogene inhibition by geldanamycin derivatives: synthesis, mechanism of action, and structureactivity relationships. J Med Chem 38: 3813-3820 (1995)

34. Schnur RC, Corman ML, Gallaschun RJ, Cooper BA, Dee MF, Doty JL, Muzzi ML, Moyer JD, DiOrio CI, Barbacci $\mathrm{EG}$, et al. Inhibition of the oncogene product p185erbB-2 in vitro and in vivo by geldanamycin and dihydrogeldanamycin derivatives. J Med Chem 38: 3806-3812 (1995)

35. Floss HG, Yu TW. Rifamycin-mode of action, resistance, and biosynthesis. Chem Rev 105: 621-632 (2005)

36. Egorin MJ, Zuhowski EG, Rosen DM, Sentz DL, Covey JM, Eiseman JL. Plasma pharmacokinetics and tissue distribution of 17-(allylamino)-17-demethoxygeldanamycin (NSC 330507) in CD2F1 mice1. Cancer Chemother Pharmacol 47: 291-302 (2001) 